\title{
Investigation of clinical and genetic factors in patients with deep vein thrombosis. A retrospective study
}

\author{
Nihal İnandıklıoğlu', Haci Alper Uzun², Ferit Çiçekçioğlu² \\ 'Department of Medical Biology, Faculty of Medicine, Yozgat Bozok University, Turkey \\ ${ }^{2}$ Department of Cardiovascular Surgery, Faculty of Medicine, Yozgat Bozok University, Yozgat, Turkey
}

\begin{abstract}
Introduction: Generally, risk factors for deep vein thrombosis (DVT) include advanced age, surgery, fractures, pregnancy, puerperium, use of oral contraceptives, hormone replacement therapy, cancer and genetics associated with the hemostatic system in influencing thrombotic risk. The aim of this study was to evaluate routine complete blood count parameters, the clinical and genetic data of patients with diagnosis of DVT in our hospital and to contribute to the literature with our results.

Material and methods: This retrospective study included a total of 152 patients (67 males and 85 females) diagnosed with DVT between January 2016 and September 20 19. The history, clinical findings, venous doppler ultrasonography and genetic analysis results of patients were evaluated.

Results: The study included I 52 DVT patients. When the lower extremity venous doppler ultrasonography (VDU) results were evaluated, venous insufficiency was detected in 126 patients (82.9\%), 57 of whom were male and 69 were female. Genetic results of F2 G202 I OA, FVL GI69IA, MTHFR C677T and MTHFRAI $298 \mathrm{C}$ were examined. FLV gene distributions were statistically different between genders (38.8\% of men; $16.5 \%$ of women). This difference was also statistically significant ( $p=0.003)$.

Conclusion: The hemogram parameters were found to be insufficient markers. VDU was seen to be a clinically necessary marker in diagnosis; and genetic outcomes were important in initiating appropriate treatment in the early period. These results also show that there are differences according to gender in determining thrombotic risk.
\end{abstract}

Key words: thrombosis, deep vein thrombosis, genetics, factor $V$ Leiden

Acta Angiol 2020; 26, 3: 96-101

\section{Introduction}

Venous thromboembolism (VTE) is the general term for all pathological thrombosis arising in the venous circulation, which clinically includes pulmonary embolism (PE) and deep vein thrombosis (DVT). DVT is usually defined as a clot that forms in the deep veins of the lower extremities, impairing the circulation by blocking the vessel [I]. Deep vein thrombosis is an important cause of mortality and morbidity since it is a cause of pulmonary embolism and post-thrombotic syndrome. Advanced age, immobility, trauma, history of surgical operation and malignancy are conditions that increase the tendency to develop DVT [2]. The diagnostic tools for the diagnosis of DVT are limited in primary care. The patient's history and classic clinical findings on physical examination alone are not sufficient to diagnose or exclude DVT. In order to reliably exclude DVT, a pre-test probability scoring of DVT, called the Wells' scoring developed by Wells et al. [3], is used for 
the diagnosis. Following the Wells' scoring, DVT is diagnosed by $\mathrm{D}$-dimer and venous doppler ultrasonography performed on patients.

Venous doppler ultrasonography (VDU) is the standard imaging test for patients suspected of having lower extremity DVT. The sensitivity of VDU is $97 \%$ for proximal DVT, while it is $73 \%$ for calf veins, and may remain inadequate for calf veins in asymptomatic patients. Compression VDU performed at certain intervals allows imaging of all leg and calf veins [4]. VDU makes it easier for the physician to diagnose or exclude the disease. In addition, another important factor is genetic findings that allows for easier treatment of DVT for the physician. The genetic factors include factor $V$ Leiden (FVL) GI69IA, methylenetetrahydrofolate reductase (MTHFR) C677T and A I298C, and coagulation factor II (FII) G202 I OA polymorphism regions [5]. FVL is the most common cause of hereditary thrombophilia and is resistant to protein $\mathrm{C}$. The risk of thrombosis is increased 5 -fold in heterozygotes and 50 -fold in homozygotes. FII G202IOA mutation is also among the causes of hereditary thrombophilia. Patients with FVL GI69IA and FII G202I0A compound heterozygotes carry a twenty-fold increased risk of thrombosis compared to those with both mutations [5, 6]. Hyperhomocysteinemia (elevation of homocysteine level) may be both genetic and acquired. MTHFR is an enzyme involved in homocysteine metabolism. The most common genetic causes of hyperhomocysteinemia are the C677T and AI298C mutations that lead to MTHFR enzyme deficiency. Although hyperhomocysteinemia is an independent risk factor for atherosclerotic vascular diseases, it has been reported that it increases the risk of venous thrombosis and is associated with DVT $[5,7]$. Evaluation of these factors is important in diagnosis and treatment of the disease.

In our study, we retrospectively evaluated demographic characteristics, reasons for admission to hospital, physical examination findings, DVT localization (determined by VDU) and genetic findings of patients, who received a diagnosis of DVT, and aimed to determine whether an acute attack can be predicted in the diagnosis, treatment and/or whether an acute attack had an effect on markers.

\section{Material and methods}

The study included a total of 152 patients, 85 females (55.9\%) and 67 males (44.1\%), diagnosed with lower extremity DVT. Patients who had a DVT attack for the first time were included in the study. The patients were diagnosed by clinical symptoms and VDU results. Patients with known heritable diseases were excluded. The routine hemogram results, clinical findings and genetic results of these patients were retrospectively evaluated. The ethical approval for our study was obtained from the Ethics Committee of Bozok University, Faculty of Medicine, Turkey (document no: 2017-KAEK189_2019.06.26_07). The study was conducted in accordance with the principles of the Helsinki Declaration of the World Medical Association. All participants gave informed written consent.

\section{Statistics}

SPSS 17.0 (SPSS Inc., Chicago, Illinois, USA) was used for the statistical analysis of the data. Categorical measurements were expressed as number and percentage, and continuous measurements were expressed as mean and standard deviation (median and minimum-maximum, where necessary). The Chi-square test or Fisher's exact test were used to compare categorical variables. Normality distributions were checked in the comparison of continuous measurements between groups; the Mann-Whitney $U$ test was used since the parametric distribution did not provide precondition assumption. The correlation between the variables was determined by Spearman's correlation coefficient. The level of statistical significance was taken as $\mathbf{0 . 0 5}$ in all tests.

\section{Results}

Of the I52 DVT patients participated in the study, 85 were female and 67 were male. The mean age of the patients was $48.6 \pm 12.2$ years, $46.9 \pm 11.8$ years for females, and $50.8 \pm 12.4$ years for males. In general, the admission complaints were pain, swelling and accompanying redness in $87 \%$ of the patients. When the hemogram results of the DVT patients included in the study were examined, all values were found to be within the normal range in both males and females. When the results were statistically evaluated by gender, it was found that there was a significant difference between the male and female patients in terms of eosinophil, erythrocyte, hematocrit, hemoglobin, mean cell hemoglobin $(\mathrm{MCH})$, mean corpuscular hemoglobin concentration (MCHC) and procalcitonin (PCT) values (Table I). When we evaluated the hemogram results of our patients in the light of the data obtained, we found a significant difference between the female and male patients depending on gender in eosinophil $(p=0.025)$, erythrocyte $(p=0.003)$, hematocrit $(p=0.000)$, hemoglobin $(p=0.000), M C H(p=$ $0.010), M C H C(p=0.014)$ and PCT $(p=0.009)$ values. When the results of lower extremity VDU were evaluated, the VDU findings were found to be normal in 26 patients ( $17.1 \%), 13$ of whom were male and 13 of whom were female. However, venous insufficiency was 
detected in 126 patients (82.9\%), 57 of whom were male and 69 of whom were female. Thirty $(23.8 \%)$ patients had deep venous insufficiency in at least one vein. Of the patients, $6 \mathrm{I}(48.4 \%)$ had venous thrombosis in the left lower extremity, 47 (37.3\%) in the right lower extremity, and 18 (14.3\%) had venous thrombosis both in the right and left lower extremities. It was found that fifty-four patients ( $42.8 \%$ ) had DVT in the great saphenous vein (GSV), 47 (37.3\%) in the femoral vein, $28(22.2 \%)$ in the popliteal vein, $19(15 \%)$ in the tibial vein, and 7 (5.5\%) had DVT in the iliac vein.

Genetic results of FII, FVL and MTHFR genes were also evaluated to help early treatment. When the FII gene $\mathrm{G} 202 \mathrm{I}$ OA polymorphism region was evaluated, it was found that of the 152 patients, I 42 (93.4\%) had GG normal genotype (WT) and 10 had GA heterozygous mutant $(6.6 \%)(\mathrm{HT})$ genotype. None of the patients had AA homozygous mutant (HM) genotype. When the FVL gene GI69IA polymorphism region was evaluated, it was found that of the 152 patients, $106(69.7 \%)$ had GG (WT), 40 (26.3\%) had GA (HT) and 6 (3.9\%) had AA (HM) genotypes. When the MTHFR gene C677T polymorphism region was evaluated, it was found that of the I 52 patients, 82 (53.9\%) had CC (WT), 57 (37.5\%) had CT (HT) and $13(8.6 \%)$ had TT (HM) genotypes. When the MTHFR gene AI 298 C polymorphism region was evaluated, it was found that of the 152 patients, 5 I (33.5\%) had AA (WT), 8I (53.3\%) had AC (HT) and 20 (I3.2\%) had CC (HM) genotypes. When the genetic findings were statistically evaluated by gender, it was found that there was a significant difference in male heterozygous individuals in terms of FVL GI69IA polymorphism region ( $p=0.003) .38 .8 \%$ of men were heterozygous while $16.5 \%$ of women were heterozygous. In addition, the proportion of individuals who were normal is higher in women than in men (Table I, Fig. I). Moreover, it was found that II of the 152 patients had no genotypic change, while 68 patients had more than one mutation. It was determined that 38 patients had heterozygous mutations in two genes, 17 patients had heterozygous mutations in three genes, 10 patients had one heterozygous and one homozygous mutations, 2 patients had two heterozygous mutations, and I patient had two homozygous mutations.

\section{Discussion}

It is known DVT affects approximately $0.1 \%$ of people annually and the incidence rises with increasing age. It is a disease with a high morbidity and mortality rate when not diagnosed and treated early. It may cause pulmonary embolism, venous gangrene, chronic venous insufficiency, venous hypertension and post-thrombotic syndromes [6]. The signs and symptoms of DVT are nonspecific and specific tests are required for the diagnosis [8]. In the etiology of DVT, the findings of hemogram, VDU and genetic analysis are helpful in the diagnosis and treatment process and in preventing post-treatment complications. In our study, we evaluated whether an acute attack could be predicted in the diagnosis and treatment by using hemogram, clinical and genetic parameters of DVT patients and/or whether an acute attack had an effect on markers.

In DVT, hemogram findings may provide important data at the time of initial diagnosis, but are insufficient alone. Some studies in the literature have reported that there might be a correlation between certain hemogram parameters and DVT. In their study, Zorlu et al. [9] emphasized that increased red cell distribution width (RDW) poses an increased risk of mortality in acute pulmonary embolism patients. In another study, Cay et al. found a significant correlation especially between high RDW level and the presence and severity of non-chronic proximal DVT in patients with DVT [10]. In another study on Turkish patients, the mean platelet volume (MPV), an indicator of platelet activation, was found to be higher in patients with DVT than in the control group [II]. When we evaluate the hemogram results of our patients in the light of the data obtained, we found a significant difference between the female and male patients depending on gender in eosinophil $(p=0.025)$, erythrocyte $(p=0.003)$, hematocrit $(p=0.000)$, hemoglobin $(p=0.000), M C H(p=0.010)$, MCHC $(p=0.014)$ and PCT $(p=0.009)$ values. VDU findings have an important role in the diagnosis of DVT and even provide great convenience to the physician in the diagnosis of patients whose diagnosis has been missed on the initial examination. Of venous thrombosis, $85 \%$ occur in the tibial vein, $9 \%$ in the popliteal fossa, and $6 \%$ occur in the thigh veins. Of venous thrombosis, $35 \%$ is bilateral. It occurs more commonly in the left lower extremity [12]. In a retrospective study evaluating VDU results of I,328 Turkish patients, $26.7 \%$ of the patients were found to have deep venous insufficiency in at least one vein [13]. According to the VDU results evaluated in another study, $62.4 \%$ of patients were found to have thrombosis in the left lower extremity and $37.6 \%$ were found to have thrombosis in the right lower extremity. Of these patients, $41.6 \%$ had DVT in the femoral vein, $31.8 \%$ in the iliac vein and $26.6 \%$ had DVT in the popliteal vein and its distal [14]. According to VDU results evaluated in the present study, $80.3 \%$ of our patients ( 122 patients) were found to have venous insufficiency. In light of these results, we see that VDU findings have an important place in the diagnosis of DVT and provide great convenience to the physician in the diagnosis, although hemogram findings do not show any variability. 
Table I. Demographic data of the patients

\begin{tabular}{|c|c|c|c|c|}
\hline & Women & Men & Total & $\mathbf{p}$ \\
\hline Participants (n) & 85 & 67 & 152 & \\
\hline \multicolumn{5}{|c|}{ Risk factors and biological data } \\
\hline Age (years) & $46.9 \pm 11.8$ & $50.8 \pm 12.4$ & $48.6 \pm 12.2$ & 0.146 \\
\hline Gender (\%) & 55.9 & 44.1 & 100 & \\
\hline WBC $\left(10^{3} / \mathrm{mm}^{3}\right)$ & $8.1 \pm 1.8$ & $8.4 \pm 2.2$ & $8.2 \pm 1.9$ & 0.534 \\
\hline Neutrophil $\left(10^{3} / \mathrm{mm}^{3}\right)$ & $5.0 \pm 1.7$ & $5.2 \pm 1.8$ & $5.1 \pm 1.7$ & 0.524 \\
\hline Lymphocytes $\left(10^{3} / \mathrm{mm}^{3}\right)$ & $2.3 \pm 0.5$ & $2.4 \pm 0.9$ & $2.3 \pm 0.7$ & 0.778 \\
\hline Monocytes $\left(10^{3} / \mathrm{mm}^{3}\right)$ & $0.6 \pm 0.1$ & $0.6 \pm 0.2$ & $0.6 \pm 0.1$ & 0.057 \\
\hline Eosinophil $\left(10^{3} / \mathrm{mm}^{3}\right)$ & $0.1 \pm 0.07$ & $0.2 \pm 0.1$ & $0.2 \pm 0.1$ & $0.025 *$ \\
\hline Basophil $\left(10^{3} / \mathrm{mm}^{3}\right)$ & $0.05 \pm 0.02$ & $0.05 \pm 0.02$ & $0.05 \pm 0.02$ & 0.197 \\
\hline Neutrophil (\%) & $60.5 \pm 7.7$ & $60.5 \pm 9.9$ & $60.5 \pm 8.7$ & 0.803 \\
\hline Lymphocytes (\%) & $29.9 \pm 6.8$ & $29.3 \pm 9.3$ & $29.6 \pm 7.9$ & 0.415 \\
\hline Monocytes (\%) & $7.1 \pm 1.2$ & $7.3 \pm 1.3$ & $7.2 \pm 1.2$ & 0.089 \\
\hline Eosinophil (\%) & $1.8 \pm 0.8$ & $2.2 \pm 1.4$ & $1.9 \pm 1.1$ & 0.144 \\
\hline Basophil (\%) & $0.6 \pm 0.2$ & $0.6 \pm 0.2$ & $0.6 \pm 0.2$ & 0.110 \\
\hline Erythrocyte $\left(10^{3} / \mathrm{mm}^{3}\right)$ & $4.8 \pm 0.4$ & $5.1 \pm 0.5$ & $4.9 \pm 0.4$ & $0.003 *$ \\
\hline Hemoglobin (g/dL) & $13.4 \pm 1.3$ & $14.4 \pm 1.7$ & $13.8 \pm 1.5$ & $0.000 *$ \\
\hline Hematocrit (\%) & $41.2 \pm 3.7$ & $43.6 \pm 4.2$ & $42.2 \pm 4.1$ & $0.000 *$ \\
\hline $\mathrm{MCV}(\mathrm{fl})$ & $84.9 \pm 4.5$ & $86.0 \pm 3.5$ & $85.4 \pm 4.1$ & 0.279 \\
\hline $\mathrm{MCH}(\mathrm{fl})$ & $27.6 \pm 1.8$ & $28.3 \pm 1.8$ & $27.9 \pm 1.8$ & $0.010 *$ \\
\hline $\mathrm{MCHC}(\mathrm{g} / \mathrm{dL})$ & $32.6 \pm 1.1$ & $32.8 \pm 1.4$ & $32.6 \pm 1.2$ & $0.014 *$ \\
\hline RDW-CV (\%) & $13.9 \pm 1.2$ & $13.9 \pm 1.5$ & $13.9 \pm 1.4$ & 0.646 \\
\hline Platelets $\left(10^{3} / \mathrm{mm}^{3}\right)$ & $284.8 \pm 52.2$ & $266.1 \pm 53.8$ & $276.6 \pm 53.5$ & 0.162 \\
\hline PCT (\%) & $0.3 \pm 0.05$ & $0.3 \pm 0.05$ & $0.3 \pm 0.05$ & $0.009 *$ \\
\hline $\mathrm{MPV}(\mathrm{fL})$ & $10.5 \pm 0.7$ & $10.3 \pm 0.7$ & $10.4 \pm 0.7$ & 0.205 \\
\hline PDW & $12.3 \pm 1.7$ & $11.9 \pm 1.6$ & $12.2 \pm 1.6$ & 0.502 \\
\hline NRBC (fL) & $0.002 \pm 0.005$ & $0.004 \pm 0.02$ & $0.003 \pm 0.01$ & 0.510 \\
\hline NRBC (\%) & $0.02 \pm 0.04$ & $0.03 \pm 0.14$ & $0.02 \pm 0.09$ & 0.411 \\
\hline IG & $0.05 \pm 0.07$ & $0.07 \pm 0.12$ & $0.06 \pm 0.1$ & 0.105 \\
\hline IG (\%) & $0.5 \pm 0.5$ & $0.8 \pm 1.5$ & $0.6 \pm 1.06$ & 0.066 \\
\hline PLCR (\%) & $28.2 \pm 5.3$ & $27.3 \pm 5.2$ & $27.8 \pm 5.3$ & 0.551 \\
\hline \multicolumn{5}{|l|}{ Genetics data } \\
\hline \multirow{2}{*}{$\begin{array}{l}\text { FII G20210A } \\
\text { WT }\end{array}$} & & & & 0.187 \\
\hline & 77 (\%90.6) & 65 (\%97) & 142 (\%93.4) & \\
\hline $\mathrm{HT}$ & 8 (\%9.4) & $2(\% 3)$ & $10(\% 6.6)$ & \\
\hline \multirow{2}{*}{$\begin{array}{l}\text { FVL GI69IA } \\
\text { WT }\end{array}$} & & & & $0.003 *$ \\
\hline & 69 (\%8I.2) & 37 (\%55.2) & 106 (\%69.7) & \\
\hline $\mathrm{HT}$ & $14(\% \mid 6.5)$ & $26(\% 38.8)$ & $40(\% 26.3)$ & \\
\hline HM & $2(\% 2.4)$ & $4(\% 6)$ & $6(\% 3.9)$ & \\
\hline \multirow{2}{*}{$\begin{array}{l}\text { MTHFR C677T } \\
\text { WT }\end{array}$} & & & & 0.612 \\
\hline & $48(\% 56.5)$ & $34(\% 50.7)$ & $82(\% 53.9)$ & \\
\hline $\mathrm{HT}$ & 29 (\%34.I) & $28(\% 4 I .8)$ & 57 (\%37.5) & \\
\hline $\mathrm{HM}$ & 8 (\%9.4) & $5(\% 7.5)$ & $13(\% 8.6)$ & \\
\hline \multirow{2}{*}{$\begin{array}{l}\text { MTHFR AI } 298 C \\
\text { WT }\end{array}$} & & & & 0.500 \\
\hline & $30(\% 35.3)$ & 21 (\%3।.3) & $5 \mathrm{I}(\% 33.6)$ & \\
\hline $\mathrm{HT}$ & $42(\% 49.4)$ & $39(\% 58.2)$ & 81 (\%53.3) & \\
\hline $\mathrm{HM}$ & $13(\% \mid 5.3)$ & 7 (\% $\% .4)$ & $20(\% \mid 3.2)$ & \\
\hline
\end{tabular}

Values presented as mean \pm standard deviation; *p < 0.05; IG: immature granulocyte; MCV: mean corpuscular volume; $\mathrm{MCH}$ : mean cell hemoglobin; $\mathrm{MCHC}$ : mean corpuscular hemoglobin concentration; MPV: mean platelet volume; NRBC: erythroblasts; PCT: procalcitonin; PDW: platelet distribution width; PLCR: platelet large cell ratio; RDW-CV: red cell distribution width \%; WBC: leucocytes 


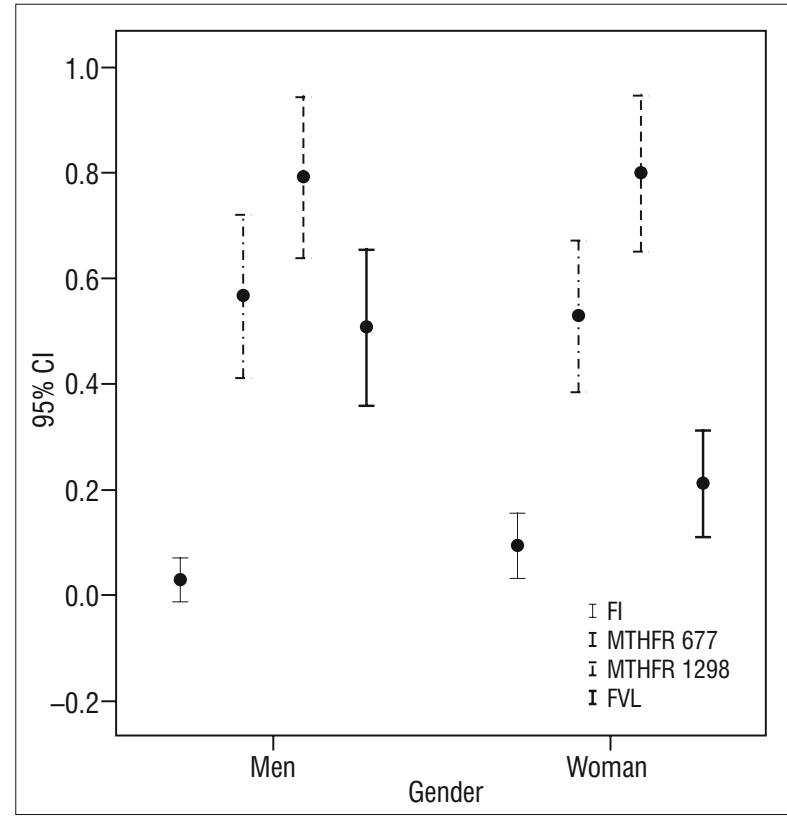

Figure I. In the diagram, genetic changes according to gender are presented in $95 \%$ confidence interval

In the literature, there are many studies analyzing the genetic risk factors in the etiology of DVT in different ethnic populations [15, I6]. In various studies, FII G20210A, FVL GI69IA, MTHFR C677T and MTHFR AI298C polymorphism regions especially have been reported to be risk factors in venous thrombosis $[5,7,17]$. In a study on the Croatian population, the FVL GI69IA mutation was identified to be the most common and the FII gene G202 I0A was identified to be the second most common mutation [18]. In a similar study on Iranian DVT patients, FVL GI69IA was found to be the most common mutation. In addition, it was emphasized that it is more common in female patients [19]. In another study on the Iranian population, FVL GI69।A, MTHFR C677T and MTHFR AI298C mutations were associated with increased risk of DVT. However, it was indicated that G20210A mutation in the FII gene was not a risk factor for DVT [20]. In a meta-analysis study with a large sample size, FVL G I 69 IA and FII G202 I0A mutations were identified to be moderate risk factors for vascular thromboembolism. The risk was found to increase in FVL GI69IA and FII G20210A heterozygous carriers but not associated with MTHFR C677T mutation [2I]. There are also other studies showing no correlation between MTHFR C677T polymorphism and venous thrombosis [22]. In a similar study on the Turkish population, it was stated that there was a correlation between MTHFR C677T polymorphism and DVT, but the same results were not found for MTHFR AI298C polymorphism [23]. When we evaluated our results based on these data, we could not identify a homozygous mutation for the FII G202 I AA polymorphism region. We identified heterozygous mutations in $6.6 \%$ of the patients. In terms of the FVL GI69IA polymorphism region, we found that of the patients, $26.3 \%$ had heterozygous mutation and $3.9 \%$ had homozygous mutation. In contrast to the results of the study conducted on the Iranian population, we found it to be higher in male patients than in female patients $(p=0.003)$ [19]. We found that of the patients, $37.5 \%$ had the heterozygous mutation, $8.6 \%$ had the homozygous mutation for the MTHFR C677T polymorphism region, $53.3 \%$ had the heterozygous mutation and $13.2 \%$ had the homozygous mutation for the AI298C polymorphism.

In conclusion, there were many factors affecting the etiology of DVT. In this study, hemogram, clinical and genetic parameters of DVT patients were evaluated. In light of the data, the hemogram parameters were found not to be sufficient markers. VDU was found to be a clinically necessary marker in diagnosis, together with genetic outcomes, in initiating appropriate early-phase treatment. Whether thrombotic events occur due to genetic predispositions that differ according to gender requires studies with larger populations. Subsequent studies will be needed to further our knowledge on these issues.

\section{Acknowledgements}

The authors would like to thank the reviewers for their constructive and invaluable comments.

\section{Conflict of interest}

None.

\section{References:}

I. Demir M, Erdemli B, Kurtoğlu M, Öngen G. Ulusal Venöz Tromboembolizm Profilaksi ve Tedavi Kılavuzu. İstanbul. Diasan Press, Cortex 2010.

2. Toll D. Excluding deep vein thrombosis in primary care: validation, updating, and implementation of a diagnostic rule. Utrecht University, 2008.

3. Wells PS, Anderson DR, Rodger M, et al. Evaluation of D-dimer in the diagnosis of suspected deep-vein thrombosis. N Engl J Med. 2003; 349(13): I227-I235, doi: 10.1056/NEJMoa023 I53, indexed in Pubmed: 14507948.

4. Tick LW, Ton E, van Voorthuizen T, et al. Practical diagnostic management of patients with clinically suspected deep vein thrombosis by clinical probability test, compression ultrasonography, and D-dimer test. Am J Med. 2002; I 13(8): 630-635, doi: 10.1016/ s0002-9343(02)0 1347-5, indexed in Pubmed: $12505 \mid 12$.

5. Rosendaal FR, Reitsma PH. Genetics of venous thrombosis. J Thromb Haemost. 2009; 7 Suppl I: 30I-304, doi: 
10.1 III/j.1538-7836.2009.03394.x, indexed in Pubmed: |963082I.

6. White RH. The epidemiology of venous thromboembolism. Circulation. 2003; 107(23 Suppl 1): 14-18, doi: 10.1161/01. CIR.0000078468.1 1849.66, indexed in Pubmed: I28| 4979.

7. Spiroski I, Kedev S, Antov S, et al. Methylenetetrahydrofolate reductase (MTHFR-677 and MTHFR-1298) genotypes and haplotypes and plasma homocysteine levels in patients with occlusive artery disease and deep venous thrombosis. Acta Biochimica Polonica. 2008; 55(3): 587-594, doi: 10.18388/abp.2008_3065.

8. Heim SW, Schectman JM, Siadaty MS, et al. D-dimer testing for deep venous thrombosis: a metaanalysis. Clin Chem. 2004; 50(7): I 136-1 147, doi: 10.1373/clinchem.2004.03 I765, indexed in Pubmed: 15142977.

9. Zorlu A, Bektasoglu G, Guven FM, et al. Usefulness of admission red cell distribution width as a predictor of early mortality in patients with acute pulmonary embolism. Am J Cardiol. $2012 \mathrm{Jan}$ I; 109(I):128-34. doi: 10.1016/j.amjcard.201 I.08.015. Epub 2011 । Sep 28. PMID. ; 21958741, doi: 10.1016/j.amjcard.2011.08.015.

10. Cay N, Unal O, Kartal MG, et al. Increased level of red blood cell distribution width is associated with deep venous thrombosis. Blood Coagul Fibrinolysis. 2013 ; 24(7): 727-731, doi: 10 1097/ MBC 0b0I3e3283626Ife .

1I. Gulcan M, Varol E, Etli M, et al. Mean platelet volume is increased in patients with deep vein thrombosis. Clin Appl Thromb Hemost. 20 I2; 18(4): 427-430, doi: I0.1 I77/10760296 I |427437, indexed in Pubmed: 22110160.

12. Kopánski Z, Cienciała A, Ulatowski Z, et al. Vergleich der Thromboserate nach laparoskopischen und konventionellen Eingriffen mittels des J125-Fibrinogen-Tests [Comparison of thrombosis rate after laparoscopic and conventional interventions with the $\mathrm{I}(125)$ fibrinogen test]. Wien Klin Wochenschr . 1996; 108(4): 105-110.

13. Öztürk H, Öztürk ŞY. Alt Extremite Venöz Doppler Ultrasonografik İnceleme Yapılan Hastaların Özellikleri. Van Tıp Dergisi. 2014; 21 (4): 193-196.

14. Tiryaki Ş, Eğilmez $H$, Işık $A O$, et al. Alt ekstremite derin ven trombozu tanısında renkli Doppler ultrasonografi. CÜ Tıp Fakültesi Dergisi. 2000; 22: 131-136.

15. Pai N, Ghosh K, Shetty S. Cause of deep venous thrombosis and pulmonary embolism in young patients from India as compared with other ethnic groups. Blood Coagul Fibrinolysis. 2012; 23(4): 257-26I, doi: 10.1097/MBC.0b0I3e328350296।, indexed in Pubmed: 22498980.

16. Guzmán N, Lanas F, Salazar LA. Influence of Amerindian mitochondrial DNA haplogroups on thrombosis susceptibility and frequency of four genetic prothrombotic variants in Southern Chilean subjects. Clin Chim Acta. 2010; 4II(5-6): 444-447, doi: 10.1016/j.cca.2010.01.007, indexed in Pubmed: 20064497.

17. Seligsohn U, Lubetsky A. Genetic susceptibility to venous thrombosis. N Engl J Med. 200I; 344(I6): |222-|23।, doi: 10.1056/ NEJM200 I04 I9344I607, indexed in Pubmed: I I 309638.

18. Alfirevic Z, Simundic AM, Nikolac N, et al. Frequency of factor II G202 IOA, factor V Leiden, MTHFR C677T and PAI-I 5G/4G polymorphism in patients with venous thromboembolism: Croatian case control study. Biochemia Medica. 20 10: 229-235, doi: $10.11613 / \mathrm{bm} .2010 .028$.

19. Janbabai G, Taghipour M, Sharifian R, et al. Survey of thrombophilia risk factors and markers in patients with deep vein thrombosis in Mazandaran Province, Northern Iran. Adv Biol Res. 2013; 7(4): 139-143, doi: 10.5829/idosi.abr.2013.7.4.823.

20. Hosseini S, Kalantar E, Hosseini MS, et al. Genetic risk factors in patients with deep venous thrombosis, a retrospective case control study on Iranian population. Thromb J. 2015; 13: 35, doi: 10.1 186/s 12959-015-0064-y, indexed in Pubmed: 26557789.

21. Simone B, De Stefano V, Leoncini E, et al. Risk of venous thromboembolism associated with single and combined effects of Factor V Leiden, Prothrombin 20210A and Methylenetethraydrofolate reductase $\mathrm{C} 677 \mathrm{~T}$ : a meta-analysis involving over II,000 cases and 21,000 controls. Eur J Epidemiol. 2013; 28(8): 62 I-647, doi: 10.1007/s 10654-013-9825-8, indexed in Pubmed: 23900608.

22. Bezemer ID, Doggen CJM, Vos HL, et al. No association between the common MTHFR 677C->T polymorphism and venous thrombosis: results from the MEGA study. Arch Intern Med. 2007; 167(5): 497-50I, doi: 10.100I/archinte.167.5.497, indexed in Pubmed: 17353498.

23. Akar N, Akar E, Akçay R, et al. Effect Of Metylenetetrahydrofolate Reductase 677 C-T, 1298 A-C, and 1317 T-C on Factor V 1691 Mutation in Turkish Deep Vein Thrombosis Patients. Thrombosis Research. 2000; 97(3): 163-167, doi: 10.1016/ s0049-3848(99)00I57-7. 